\title{
Uji Vulkanisat Rubber Cone Berbahan Baku Perpaduan Karet Nitril Butadiena Dan Karet Alam
}

\section{The Testing for Nitrile Butadiene Rubber and Natural Rubber Composite of Rubber Cone Vulcanizates}

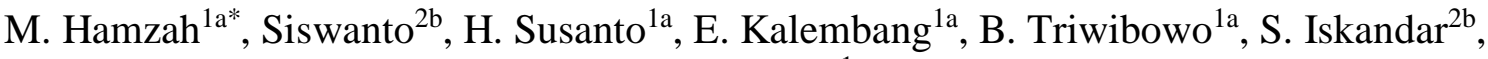 \\ D.A. Fitriani ${ }^{1 \mathrm{a}}$ \\ ${ }^{1}$ Pusat Teknologi Material, Badan Pengkajian dan Penerapan Teknologi \\ ${ }^{2}$ Pusat Pengkajian Industri Proses dan Energi, Badan Pengkajian dan Penerapan Teknologi \\ ${ }^{\mathrm{a}}$ Gedung 224 - PTM, Kawasan Puspiptek Serpong, Tangerang Selatan, 15314 \\ ${ }^{\mathrm{b}}$ Gedung 720 Lantai 2, Klaster Inovasi dan Bisnis Teknologi, Kawasan Puspiptek Serpong, \\ Tangerang Selatan, 15314 \\ *Surel: moh.hamzah@bppt.go.id.
}

\section{INFO ARTIKEL}

Diterima 8 April 2020

Direvisi 11 Juni 2020

Disetujui 16 Juli 2020

Nomor Artikel 202104

Halaman 23-28

\section{Kata kunci:}

rubber cone

pompa angguk

karet alam

karet nitril butil

tensile strength

\begin{abstract}
Rubber cone is a technical rubber product as a mechanical seal part in the stuffing box of sucker rod pump which is the main equipment for pumping crude oil from the oil. Rubber cones as consummable parts are needed in a large quantity and mostly made from synthetic nitrile butadiene rubber (NBR) which has good resistance to friction and oil, and are still imported. This research is subjected to formulate a rubber cone compound from NBR-natural rubber composite and expected to meet the technical specifications of rubber cone that will work in high load operation, resistant to friction, oil and high temperature. The rubber cone vulcanizates are tested for tensile strength and hardness based on ASTM D412 standards then compared to the technical specifications of commercial rubber cones. Tensile strength test results that the NBR-natural rubber composite formula with a ratio of $70: 30$ the value of $157.47 \mathrm{~kg} / \mathrm{cm}^{2}$ has exceeded $140.6 \mathrm{~kg} / \mathrm{cm}^{2}$ of commercial rubber cone's technical specification. The hardness shore, the properties of rubber cones vulcanizates, have range from 91 to 92 shore $A$ and after ageing treatment from 91 to 93 shore A. So, natural rubber can replace $30 \%$ amount in rubber cone compound formulation.
\end{abstract}

Keywords: rubber cone, sucker rod pump, natural rubber, nitrile butadiene rubber, tensile strength.

\begin{abstract}
Abstrak
Rubber cone adalah produk karet teknik sebagai mechanical seal part pada stuffing box pompa angguk untuk memompa minyak mentah dari dalam perut bumi. Rubber cone dikategorikan sebagai consummable part sehingga dibutuhkan dalam jumlah besar, terbuat dari karet sintetis nitril butadiena (NBR) yang memiliki ketahanan yang baik terhadap gesekan dan minyak, dan masih diimpor. Penelitian ini bertujuan untuk menformulasikan kompon rubber cone perpaduan dari NBRkaret alam dan diharapkan memenuhi spesifikasi teknis rubber cone yang akan bekerja dalam operasi beban tinggi, tahan terhadap gesekan, minyak dan suhu tinggi. Vulkanisat rubber cone diuji kekuatan tarik dan kekerasannya berdasarkan standar ASTM D412 kemudian dibandingkan dengan spesifikasi teknis rubber cone komersial. Uji kekuatan tarik formula komposit karet alam-NBR dengan rasio 70:30 menghasilkan nilai sebesar $157,47 \mathrm{~kg} / \mathrm{cm}^{2}$. Nilai ini telah melebihi nilai spesifikasi teknis rubber cone komersial, yaitu sebesar $140,6 \mathrm{~kg} / \mathrm{cm}^{2}$. Nilai kekerasan shore A dari vulkanisat rubber cone memiliki rentang 91 hingga 92 shore A dan setelah ageing nilainya meningkat dari 91 hingga 93 shore A. Jadi karet alam dapat menggantikan 30\% dalam formulasi kompon rubber cone.

Kata kunci: rubber cone, pompa angguk, karet alam, karet nitril butil, tensile strength.
\end{abstract}




\section{PENDAHULUAN}

Minyak bumi saat ini masih menjadi sektor utama untuk mendukung ketahanan energi nasional sehingga kegiatan eksplorasi dan eksploitasi minyak bumi masih gencar dilakukan untuk memenuhi kebutuhan energi nasional. Kegiatan eksploitasi minyak bumi sendiri perlu dilakukan dengan sangat efektif dan efisien untuk mempertahankan atau bahkan meningkatkan kapasitas produksi yang sudah ada. Kemampuan sebuah ladang minyak untuk mempertahankan dan meningkatkan kapasitas produksinya dipengaruhi oleh banyak faktor, di antaranya adalah kinerja dari peralatan yang digunakan dalam proses eksploitasi atau pengeboran dan manajemen pemeliharaan peralatan yang baik untuk mendukung proses eksploitasi keseluruhan.

Peralatan utama yang digunakan dalam proses eksploitasi minyak bumi adalah pompa angguk (pumping oil), seperti tersaji pada Gambar 1.

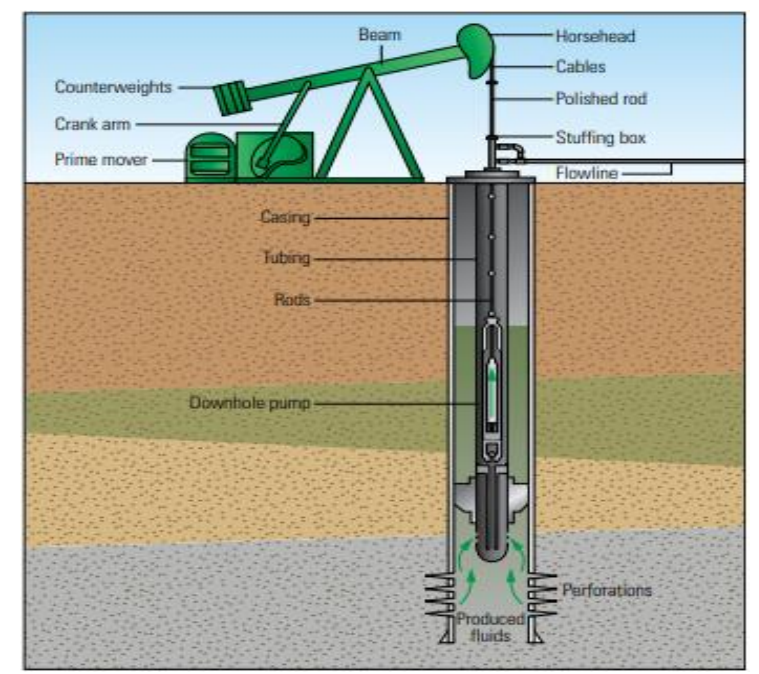

Gambar 1. Pompa angguk [1].

Pompa angguk digunakan untuk mengangkat crude oil dari dalam perut bumi ke permukaan, sehingga peran pompa angguk sangat krusial dan perlu dijaga. Salah satu komponen pompa angguk yang rentan terhadap kegagalan fungsi adalah stuffing box. Bagian ini berfungsi untuk mencegah atau menahan minyak yang dipompa menyebar seiring dengan naik turunnya polished rod.

Dalam stuffing box terdapat mechanical seal part yang terbuat dari karet atau disebut juga rubber cone. Fungsi utama rubber cone adalah mencegah terjadinya kebocoran pada daerah dimana pompa menembus chasing. Prinsip kerja dari rubber cone adalah sebagai berikut, jika pompa bekerja dengan suction lift dan tekanan pada ujung rubber cone lebih rendah dari tekanan atmosfer, maka rubber cone berfungsi untuk mencegah kebocoran udara masuk kedalam pompa.

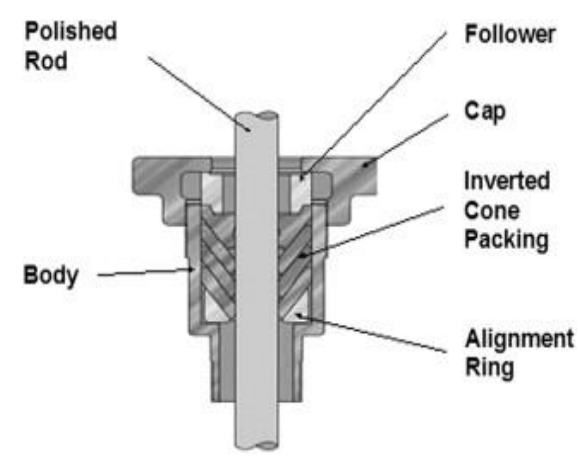

Gambar 2. Rubber cone di dalam stuffing box.

Jika tekanan pada ujung rubber cone lebih besar daripada tekanan atmosfer, maka rubber cone berfungsi untuk mencegah kebocoran cairan keluar pompa [2].

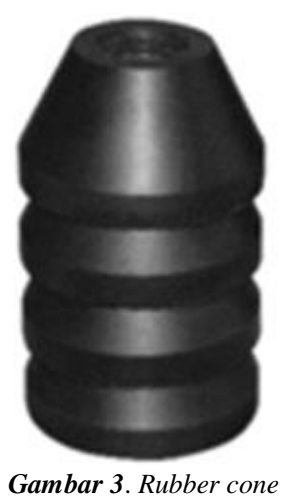

Spesifikasi teknis dari rubber cone yang dibutuhkan adalah mampu bekerja pada beban tinggi, tahan terhadap panas, tahan terhadap gesekan akibat kerja ulang-alik, dan tahan terhadap bahan kimia seperti minyak serta materi kasar seperti pasir. Rubber cone yang tersedia di pasaran saat ini adalah rubber cone berbahan baku sintetik NBR (Nitrile Butadiene Rubber) atau karet nitril merupakan karet sintetis yang tahan terhadap minyak dan gesekan [3,4]. Terbuat dari kopolimer akrilonitril dan butadiena dengan jangkauan temperatur operasinya antara $-35^{\circ} \mathrm{C}$ sampai dengan $120^{\circ} \mathrm{C}$ [5]. Spesifikasi teknis material rubber cone sebagai berikut [6]:

- Tensile strength

- Elongation : $2000 \mathrm{psi}\left(140,6 \mathrm{~kg} / \mathrm{cm}^{2}\right)$

- Specific Gravity

: $125 \% \mathrm{~min}$

- Hardness :90 shore A

Rubber cone dikategorikan sebagai consumable part sehingga diperlukan dalam jumlah besar. Namun dalam pembuatannya, rubber cone membutuhkan bahan baku karet nitril butadiena yang harus diimpor.

Vulkanisat karet alam mempunyai kepegasan pantul yang baik sehingga kalor timbulnya rendah. Tegangan putus karet alam tinggi, ketahanan sobek dan kikis juga baik, namun karet alam kurang tahan terhadap panas. Berdasarkan data Gapkindo, perkiraan produksi karet tahun 2016 sebesar 3,182 juta ton. Sementara pada tahun 2017 diproyeksikan bisa mencapai 3,277 juta ton atau naik sekitar 2,98\%. 
Sekitar 90\% produksi karet alam Indonesia diekspor ke mancanegara dan hanya sebagian kecil dikonsumsi di dalam negeri [7]. Penelitian ini bertujuan untuk membuat formula rubber cone dengan bahan baku karet gabungan antara karet nitril butadiena dan karet alam yang diharapkan dapat mensubstitusi bahan baku impor serta meningkatkan daya serap karet alam pada pembuatan produk karet teknik.

\section{METODE PERCOBAAN}

\section{Bahan}

Formula rubber cone diuraikan pada Tabel 1 di bawah ini.

Tabel 1. Formula rubber cone

\begin{tabular}{ccccc}
\hline \multicolumn{5}{c}{ Tabel 1. Formula rubber cone } \\
\cline { 3 - 5 } No & Nama Bahan & \multicolumn{3}{c}{ Formula (Phr) } \\
\cline { 3 - 5 } & & RC-1 & RC-2 & RC-3 \\
\hline 1 & NBR & 100 & 50 & 70 \\
2 & NR-SIR 10 & 0 & 50 & 30 \\
3 & STRUKTOL 40 & 1 & 1 & 1 \\
4 & Chemisil & 10 & 10 & 10 \\
5 & PEG 4000 & 0.8 & 0.8 & 0.8 \\
6 & As. Stearat & 1.5 & 1.5 & 1.5 \\
7 & Zno Red Seal & 5 & 5 & 5 \\
8 & TMQ & 2 & 2 & 2 \\
9 & GPPD & 3 & 3 & 3 \\
10 & RP3 & 3 & 3 & 3 \\
11 & COMARON RESIN & 8 & 8 & 8 \\
12 & HAF N330 & 70 & 70 & 70 \\
13 & DISP.FL & 1 & 1 & 1 \\
14 & CBS & 1.5 & 1.5 & 1.5 \\
15 & SULFUR & 2 & 2 & 2 \\
& Jumlah & 208.8 & 208.8 & 208.8 \\
\hline
\end{tabular}

Karet alam menggunakan karet NR-SIR 10 dan karet sintetis komesial NBR 7030S LG [8].

\section{Pembuatan Sampel Uji}

Proses pembuatan rubber cone terdiri dari beberapa tahap yaitu:

- Persiapan Bahan Baku

Formula rubber cone terdiri bahan baku karet sintetis nitril butadiena dan karet alam dengan variasi perbandingan, termasuk bahan aktivator dan akselerator, serta filler, bahan aditif dan bahan vulkanisator sulfur seperti tersaji pada Tabel 1.

- Proses Mastikasi

Proses mastikasi karet dilakukan selama 5 menit sampai karet homogen [9]. Proses mastikasi menggunakan open mill, seperti tersaji pada Gambar 5, dengan temperatur $70^{\circ} \mathrm{C}$, kecepatan roll $12 \mathrm{rpm}$ dan jarak antar roll $5 \mathrm{~mm}$. Kemudian ditambahkan bahan aktivator dan akselerator serta filler, bahan aditif, dan bahan vulkanisator sulfur mengikuti urutan pada Tabel 1 secara berturutturut dengan waktu gilingnya selama 15 menit.

- Pengujian Rheology

Kompon karet yang sudah homogen diambil sebagian untuk sampel uji rheology guna menentukan waktu vulkanisasi.

- Proses Vulkanisasi

Proses vulkanisasi dilakukan dengan menggunakan alat hot press pada temperatur $140^{\circ} \mathrm{C}$ selama 20 menit dan menghasilkan vulkanisat./karet matang. Penentuan waktu vulkanisasi berdasarkan waktu matang (curing time) yang didapatkan dari hasil uji rheology kompon karet, yaitu sebesar 11,42 menit. Selisih waktu uji proses vulkanisasi dimaksudkan untuk mengantisipasi bertambahnya waktu matang di alat hot press [10].

- Persiapan Sampel Pengujian Tarik dan Kekerasan Selanjutnya pembuatan sampel uji vulkanisat untuk uji kekuatan tarik dibuat dengan bantuan alat dumbell untuk membentuk sampel vulkanisat berdasarkan ASTM D412 tipe C. Sampel yaitu yang memiliki panjang $115 \mathrm{~mm}$ dengan ketebalan $2 \pm 0,2 \mathrm{~mm}$ [11]. Untuk uji kekerasan, sampel vulkanisat dibuat sesuai dengan standar Shore Hardness ASTM D2240 [12].

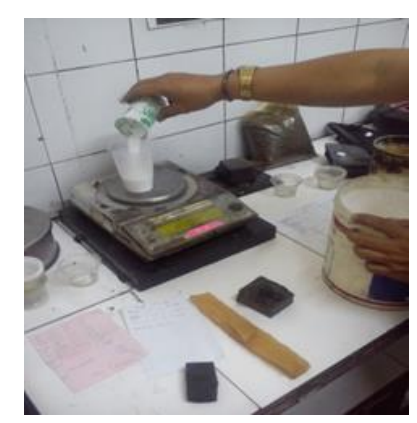

Gambar 4. Tahap penimbangan bahan baku.

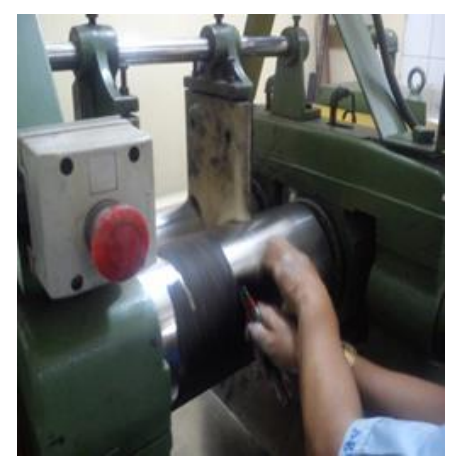

Gambar 5. Proses mastikasi kompon 


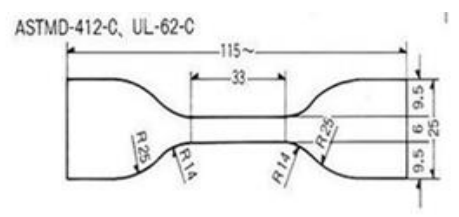

Gambar 6. Bentuk vulkanisat sampel uji

\section{Metode Pengujian}

Tensile strength atau kuat tarik didefinisikan sebagai tenaga yang dibutuhkan untuk menarik vulkanisat sampai putus. Pengujian tensile strength dilakukan dengan menggunakan alat Universal Testing Machine (UTM). Pengujian kuat tarik rubber cone ini dilakukan untuk mengetahui pengaruh antara komposisi bahan pembentuk atau bahan pengisi terhadap nilai kuat tarik yang dihasilkan. Uji ini mengacu pada ASTM D412 atau SNI ISO 37 [11]. Selain itu dapat juga dihitung tenaga yang dibutuhkan untuk menarik vulkanisat sampai perpanjangan tertentu (modulus) dan kemampuan vulkanisat meregang apabila ditarik sampai putus (elongation at break).

Secara teoritis tensile strength dihitung mengikuti rumus:

$$
T S=F / A
$$

TS: Tensile strength/nilai kuat tarik $\left(\mathrm{kg} / \mathrm{cm}^{2}\right)$

F: Gaya untuk menarik vulkanisat sampai putus (N)

A: Luas penampang vulkanisat $\left(\mathrm{cm}^{2}\right)$

Regangan atau elongation diperoleh dengan cara membagi perubahan terhadap panjang ukur awal atau gauge length awal dari sampel uji. Nilainya dihitung dengan menggunakan persamaan:

$$
\varepsilon=\left(\left(l_{1}-l_{0}\right) / l_{0}\right) x 100 \%
$$

$1_{0}$ : Panjang ukur awal sampel uji

$1_{1}$ : Panjang ukur sampel uji setelah perpanjangan

Sedangkan elongation break diperoleh pada saat $l_{1}$ pada kondisi perpanjangan di mana vulkanisat putus. Modulus merupakan nilai kuat tarik pada saat perpanjangan tertentu, misalkan modulus $100 \%$ yaitu nilai kuat tarik pada saat perpanjangan vulkanisat $2 \mathrm{x}$ dari panjang awal. Sementara itu juga dilakukan uji tarik dengan perlakuan ageing pada temperatur $70^{\circ} \mathrm{C}$ selama 48 jam.

Uji kekerasan dilakukan untuk mengetahui besarnya kekerasan vulkanisat karet dengan kekuatan penekanan tertentu berdasarkan standar Shore Hardness ASTM D2240. Kekerasan kompon karet dipengaruhi oleh adanya jumlah optimum dari penambahan bahan pengisi penguat, yang akan meningkatkan kekerasan, modulus, ketahanan sobek, ketahanan kikis dan tegangan putus. Efek penguatan bahan pengisi tersebut ditentukan oleh ukuran partikel, keadaan permukaan dan bentuk, kehalusan butiran dan kerataan penyebaran.
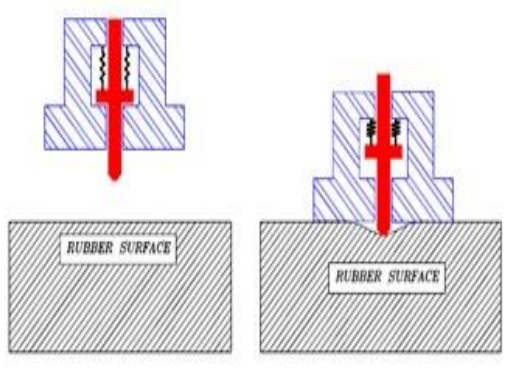

Gambar 7. Pengujian kekerasan sampel.

\section{HASIL DAN PEMBAHASAN}

Hasil uji tarik menggunakan metode ASTM D412 antara vulkanisat rubber cone karet sintetis dan karet alam terlampir pada Tabel 2.

Tabel 2. Hasil uji kekuatan tarik sebelum perlakuan ageing.

\begin{tabular}{|c|c|c|c|}
\hline \multirow{2}{*}{ PENGUJIAN } & \multicolumn{3}{|c|}{ Formula dan Rasio NBR:NR } \\
\cline { 2 - 4 } & $\begin{array}{c}\text { RC-1 } \\
\mathbf{1 0 0 : 0}\end{array}$ & $\begin{array}{c}\text { RC-2 } \\
\mathbf{5 0 : 5 0}\end{array}$ & $\begin{array}{c}\text { RC-3 } \\
\mathbf{7 0 : 3 0}\end{array}$ \\
\hline $\begin{array}{c}\text { Tensile Strength } \\
\left(\mathrm{kg} / \mathrm{cm}^{2}\right)\end{array}$ & 95.98 & 189.18 & 157.47 \\
\hline $\begin{array}{c}\text { Elongation Break } \\
(\%)\end{array}$ & 249.6 & 469.83 & 847.17 \\
\hline $\begin{array}{c}\text { Modulus 100\% } \\
\left(\mathrm{Kg} / \mathrm{cm}^{2}\right)\end{array}$ & 4.99 & 89.55 & 42.33 \\
\hline $\begin{array}{c}\text { Modulus 300\% } \\
\left(\mathrm{Kg} / \mathrm{cm}^{2}\right)\end{array}$ & - & 189.18 & 77.17 \\
\hline
\end{tabular}

Dari uji tarik menunjukkan bahwa formula RC-2, di mana ketika rasio NBR:NR 50:50, mempunyai nilai kekuatan tarik sebesar 189,18 $\mathrm{kg} / \mathrm{cm}^{2}$ dan RC-3 dengan rasio NBR:NR 70:30 memiliki nilai kekuatan tarik sebesar $157.47 \mathrm{~kg} / \mathrm{cm}^{2}$ sudah melebihi nilai karakteristik kekuatan tarik produk rubber cone komersial sebesar $140,6 \mathrm{~kg} / \mathrm{cm}^{2}$. Sedang pada formulai RC-1 dengan rasio NBR:NR 100:0 masih belum memenuhi nilai karakteristik kekuatan tarik produk rubber cone komersial.

Tabel 3. Hasil uji kekuatan tarik dengan perlakuan ageing

\begin{tabular}{|c|c|c|c|}
\hline \multirow{2}{*}{ PENGUJIAN } & \multicolumn{3}{|c|}{ Formula dan Rasio NBR:NR } \\
\cline { 2 - 4 } & $\begin{array}{c}\text { RC-1 } \\
\mathbf{1 0 0 : 0}\end{array}$ & $\begin{array}{c}\text { RC-2 } \\
\mathbf{5 0 : 5 0}\end{array}$ & $\begin{array}{c}\text { RC-3 } \\
\mathbf{7 0 : 3 0}\end{array}$ \\
\hline $\begin{array}{c}\text { Tensile Strength } \\
\left(\mathrm{kg} / \mathrm{cm}^{2}\right)\end{array}$ & 181.67 & 118,26 & 161,87 \\
\hline $\begin{array}{c}\text { Elongation } \\
\text { Break (\%) }\end{array}$ & 569 & 473,83 & 643,67 \\
\hline $\begin{array}{c}\text { Modulus 100 \% } \\
\left(\mathrm{Kg} / \mathrm{cm}^{2}\right)\end{array}$ & 67,27 & 48,40 & 52,23 \\
\hline $\begin{array}{c}\text { Modulus 300\% } \\
\left(\mathrm{Kg} / \mathrm{cm}^{2}\right)\end{array}$ & 130,60 & 88,57 & 98,94 \\
\hline
\end{tabular}


Nilai kekuatan tarik RC-1 sebesar 183,72 $\mathrm{kg} / \mathrm{cm}^{2}$ dan RC-3 sebesar $161,87 \mathrm{~kg} / \mathrm{cm}^{2}$, mengalami kenaikan setelah mendapatkan perlakuan ageing. Dengan demikian, formula RC-3 dengan rasio NBR:NR 70:30 merupakan formula yang terbaik karena tidak mengalami penurunan nilai tensile strength setelah ageing. Pada formula RC-1, nilai awal kekuatan tariknya masih di bawah nilai kekuatan tarik rubber cone komersial, sehingga belum memenuhi syarat. Namun kenaikan nilai kekuatan tarik formula RC-1 setelah ageing menunjukkan bahwa waktu proses pematangannya perlu ditambahkan agar proses crosslinking vulkanisat juga meningkat, Nilai keseluruhan elongation at break, modulus 100 dan 300 sudah terpenuhi.

\section{Perbandingan Hasil Uji Kekuatan Tarik}

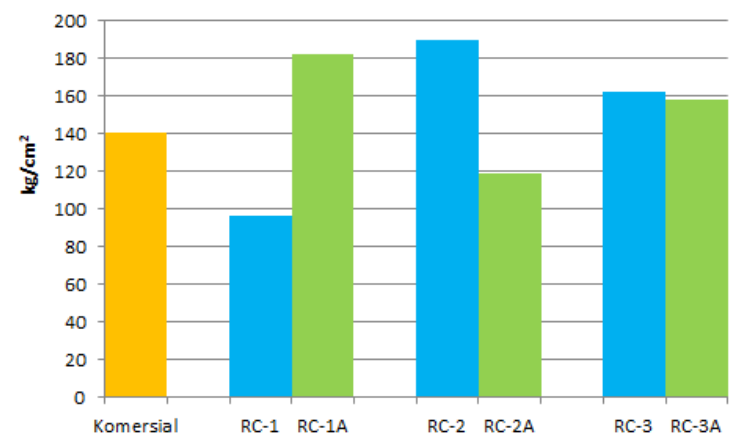

Gambar 8. Perbandingan hasil uji kekuatan tarik antara nilai karakteristik rubber cone komersial dengan vulkanisat NBR-karet alam.

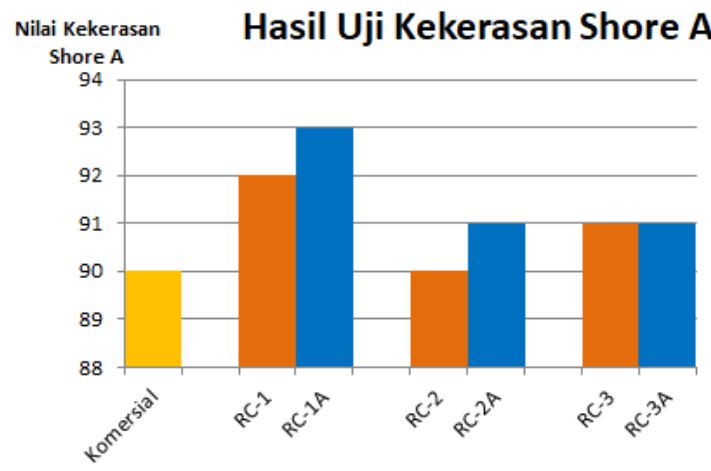

Gambar 9. Perbandingan hasil uji kekerasan shore A antara nilai karakteristik rubber cone komersial dengan vulkanisat NBR-karet alam

Nilai kekerasan rubber cone sebesar 90 sampai dengan 92 shore A sebelum ageing dan setelah mendapatkan perlakukan ageing berubah menjadi 91 sampai dengan 93 shore A. Dengan demikian, kekerasan ketiga formula lebih baik dibandingkan rubber cone komersial.

\section{KESIMPULAN DAN SARAN}

\section{Kesimpulan}

Nilai kekuatan tarik vulkanisat rubber cone komposisi karet sintetik NBR dan karet alam dengan rasio 70:30 sudah melebihi batas nilai kekuatan rubber cone komersial. Dengan demikian, karet alam dapat dipertimbangkan dalam formulasi pembuatan rubber cone. Dari hasil uji kekerasan ketiga sampel juga sudah memenuhi nilai kekerasan rubber cone komersial.

\section{Saran}

Perlu penelitian lebih lanjut pada formula komposisi NBR:karet alam dengan meningkatkan kandungan karet alam dalam pembuatan rubber cone sehingga semakin meningkat jumlah daya serap karet alam.

\section{UCAPAN TERIMA KASIH}

Penulis dan rekan mengucapkan terima kasih atas terlaksananya penelitian ini kepada Direktur Pusat Teknologi Material dalam proses pelaksanaan penelitian dan penyusunan karya tulis ilmiah ini.

\section{DAFTAR PUSTAKA}

[1] Flatern R. 'Rod Pump Systems. Oilfield Review", 2016, Available: https://www.slb.com/-/media/files/oilfieldreview/defining-rod-pumps.ashx.

[2] Takacs G. "Sucker-Rod Pumping System Components and Their Operation" in SuckerRod Pumping Handbook, Gulf Professional Publishing, 2015, Pages 57-246, Chapter 3 Sucker-Rod Pumping System Components and Their Operation.

[3] Franta I. "Elastomer and Rubber Compounding Material", 2012, Elsivier, ISBN: 978-0444569202.

[4] Omran A. M., Youssef A. M., Ahmed M. M. and Abdel-Bary E. M. "Mechanical and Oil Resistance Characteristics of Rubber Blends Based on Nitrile Butadiene Rubber. KGK rubber point", 2010, ELASTOMERE UND KUNSTSTOFFE, 63(5):197-202.

[5] Ciesielski A. "An Introduction to Rubber Technology", 1999, Rapra Technology Limited, Shawbury, United Kingdom, ISBN: 1-85957-150-6.

[6] Globaleee.com."Cone Packing”, Available: https//www.globaleee.com/ products/ stuffing-box-rubbers/cone-packing.html [tanggal akses 6 Desember 2017].

[7] Laoli N. "Proyeksi produksi karet capai 3,27 juta ton", Avalaible: http://industri.kontan.co.id/ news/ /proyeksi- 
produksi-karet-2017-capai-327-juta-ton”.

[tanggal akses 10 Mei 2017].

[8] Lgchem.com.tr. "NBR 7030 LG Chem", Available: http://m.lgchem.com.tr /products/16122012-184942-leaflet-

nbr7030s(eng)_00.pdf, [tanggal akses 5 Desember 2017]

[9] Bhowick, Hall and Benary. "Rubber Product Manufacturing Technology", Maxcel Dekker Inc. New York, 1994.

[10] Hamzah M. and Kalembang E. "Uji Rheology Kompon Karet Nitril Butil-Karet Alam", Technical Note, PTM-BPPT, 2016.

[10] ASTM D412. "Standard Test Methods for Vulcanized Rubber and Thermoplastic Elastomers-Tension”, ASTM standard.

[11] SNI ISO 37. "Karet Vulkanisat atau Termoplastik - Penentuan Sifat-Sifat Tegangan- Regangan", 2010.

[12] ASTM International. "Standard Test Method for Rubber Property-Durometer Hardness", p. 5. November 2017. doi:10.1520/D2240$15 \mathrm{E} 01$ 